\title{
Research on Regional High-Tech Innovation Efficiency and Influence Factors: Evidence from Yangtze River Economic Belt in China
}

\author{
Lin Zou $\mathbb{D}^{1,2}$ Xian-zhong Cao $\mathbb{D}^{2,3}$ and Yi-wen Zhu $\mathbb{D}^{2,3}$ \\ ${ }^{1}$ Institute of Geography, Heidelberg University, Heidelberg 69120, Germany \\ ${ }^{2}$ Center for Modern Chinese City Studies, East China Normal University, Shanghai 200062, China \\ ${ }^{3}$ Institute of Urban Development, East China Normal University, Shanghai 200062, China
}

Correspondence should be addressed to Xian-zhong Cao; xzcao@geo.ecnu.edu.cn and Yi-wen Zhu; ywzhu@geo.ecnu.edu.cn

Received 11 March 2021; Revised 6 May 2021; Accepted 21 May 2021; Published 2 June 2021

Academic Editor: Baogui Xin

Copyright $(92021$ Lin Zou et al. This is an open access article distributed under the Creative Commons Attribution License, which permits unrestricted use, distribution, and reproduction in any medium, provided the original work is properly cited.

China's high-tech innovation and marketization efficiency still need to be optimized, which restricts the promotion of regional innovation and economic development. On such practical problem, this paper mainly focuses on improvement of high-tech efficiency of China, with the hope that the research can help to find ways to improve efficiency in both regions and industry development. Moreover, the impact on the high-tech innovation stage and the marketization stage are analyzed, in order to make clear the main problems in the complex process of high-tech innovation. This paper proposed the super-SBM model and the panel regression model. The conclusions are as follows. (1) The efficiency of high-tech innovation in China is improving, but there are great differences within regions. Therefore, the heterogeneous regional innovation context should be taken into consideration in the institutional management policies. (2) There is a significant positive correlation between government subsidies and R\&D intensity in improving the high-tech innovation efficiency. Government needs to carry out appropriate policy guidance, increase financial support, and encourage high-tech enterprises to increase R\&D investment. (3) Openness and better innovation environment play a positive role in the technology marketization stage; thus, the establishment of inter-regional cooperation or transnational relations is an effect way. Forming a better innovation environment can also help to enhance international hightechnology cooperation and improve marketization efficiency.

\section{Introduction}

China's economy is not only developing rapidly but also facing multiple challenges, such as lack of core technology innovation, low efficiency of technology transformation, declining rate of economic growth, energy shortages, and environmental pollution [1]. Existing research studies have also proved that technological innovation can affect national or regional economic development and environmental improvement [2]. Therefore, it is very important to promote the regional technology innovation efficiency, especially to improve the efficiency of high-tech industries. The knowledge and technology of high-tech industry are highly concentrated, and high-tech industry has the characteristics of high investment, high risk, and high income. By using advanced technology to produce high-tech products, hightech industry can have a significant impact on the development of other industries, regional economic structure, and economic growth. The efficient development of the high-tech industry is the key for a country to realize industrial transformation and better participate in global economic competition.

The development level of the high-tech industry can reflect the national and regional technological innovation capabilities and economic development level to a certain extent, and its innovation efficiency directly affects the regional high-quality development. The added value of China's high-tech industry was $11.8 \%$ [3]; however, the low efficiency of technological innovation also restricts the improvement of its development level. Although China's high- 
tech industry creates a high industrial added value every year, can the output value be efficiently transformed into the market value? Has the industry run efficiently? Relevant research studies have pointed out that there is quite difference in the industry performance among different types of enterprises, regions, and different industrial environments. To a certain extent, this shows that the high output of the high-tech industry in some regions of China is due to the high $\mathrm{R} \& \mathrm{D}$ funds and personnel investment, which is not an effective way to improve the innovation efficiency. The economic development and technological innovation of the high-tech industry need to effectively transform the new technology or products into the market value in order to gain advantages in the competition. Therefore, how to evaluate and improve the innovation efficiency of the regional high-tech industry is the key to improve China's regional innovation and economic development. Therefore, it is necessary to analyze the problems and influencing factors that restrict the improvement of innovation efficiency in heterogeneous regions.

The high-tech industry is a technology intensive industry, which can best reflect the regional scientific and technological innovation and economic development. Its innovation efficiency will directly affect the high-quality development of the region. China's high-tech industry is developing rapidly, but there are still some problems. The escalation of international trade frictions also reflects that China's high-tech industry is still facing the key problems of scarcity of core technology and difficult marketization. The difficulty restricted the development of China's high technology development. China's high-tech industry has obvious characteristics of spatial heterogeneity. Regional advantages, resource differences, market environment, regional technical barriers, and other factors make the innovation efficiency of enterprises have obvious spatial imbalance [4]. With the continuous increase of regional high-tech industry innovation investment, how to objectively evaluate and improve the innovation efficiency has become an urgent problem. If we ignore the heterogeneity and assume that they have the same production frontier, we cannot accurately judge the innovation efficiency and technology marketization.

According to the existing research, geographic location can be an exogenous location factor, and enterprises will build on the advantage of geographic location to realize advantages [4]. The Yangtze River Economic Belt covers the Yangtze River Delta Region, central and western regions of China, which are most vibrant and representative Chinese regions with significant development potential [4]. By 2018, the region's overall population and GDP have reached almost $50 \%$ of the whole China, and it is an important region in China's economic development strategy. In recent years, the scale of high-tech industries in the Yangtze River economic belt has been expanding. The number of high-tech enterprises increased from 13,044 to 16,546 during 2009 to 2018, accounting for $49.2 \%$ of China's high-tech enterprises. High-tech enterprises' revenue in Yangtze River economic belt accounted for $45.8 \%$ of whole China, and government financial support for high-tech enterprises accounted for
49.4\%. However, regions within the Yangtze River economic belt are in different stages of industrial economic development, while the research on this region lacks accurate consideration of the heterogeneous context. Therefore, on the one hand, the Yangtze River economic belt is an important region for high-tech industry development in China. On the other hand, the obvious regional heterogeneity also makes great differences in its innovation level and efficiency [5]. The Yangtze River economic belt has become a typical region of economic and geographical research, which has strong representativeness and importance. The Yangtze River Economic Belt has achieved remarkable development in recent years, and internal heterogeneity is obvious. How to realize sustainable development of innovation resources is a strategic problem that needs to be solved urgently in China.

The innovation and transformation of the high-tech industry is a complicated process; it is a process in which participants in technology creation and marketization activities turn resources into new technology and then into productivity and realize marketization. This paper focuses on technological innovation and marketization of the high-tech industry, taking the Yangtze River economic belt as a case region, and this paper attempt to discuss the following. (1) How is the overall efficiency of high-tech industry innovation in the Yangtze River economic belt? What is the different within the heterogeneity region? (2) What is the feature of different innovation stages? How does the efficiency of each stage evolve over time? (3) What are the main factors affecting high-tech industry innovation in the Yangtze River economic belt? What is the mechanism of improving high-tech innovation efficiency?

In this paper, we mainly contribute to the existing research on high-tech efficiency in the following points. On the one hand, we focus on improvement of high-tech efficiency in representative region of China and hope the research can help to improve overall efficiency of high-tech innovation in both regions and industry development. On the other hand, we analyze not only the impact factors of the overall efficiency but also the impact of both the high-tech innovation stage and the marketization stage, in order to accurately reflect the main problems in different process of high-tech innovation. Moreover, the super-SBM model has proven to be an effective analytical tool in efficiency research; based on the model, we made more objective and distinctive values of innovation efficiency. This paper analyses high-tech innovation efficiency in Yangtze River Economic Belt, which has practical significance for empirical analysis on high-tech innovation and marketization in China's heterogeneous regions.

This paper is organized as follows. Section 2 is the review of technology innovation and innovation performance. Section 3 is is the description of data and methodology of our research. Section 4 describes heterogeneity feature and overall efficiency of the high-tech industry in Yangtze River Economic Belt. The stage efficiency of technology creation, the marketization of the high-tech industry, and the influence factor are presented in Section 5. In Section 6, we offer some concluding remarks. 


\section{Literature Review and Research Strategy}

2.1. Classification and Innovation Feature of the High-Tech Industry. In the 1960s, the word "high technology" appeared in the United States. It is used to express advanced technology that can achieve significant economic benefits. The high-tech industry is based on advanced science and technology, through high-intensity research and development to produce knowledge intensive new products. China's high-tech industry mainly includes aerospace and equipment manufacturing, medical equipment and instrument manufacturing industry, manufacturing of electronic communication equipment, medical manufacturing, and computer and office equipment manufacturing (Figure 1).

The high-tech industry is characterized by high investment, high risk, and high income [6]. The high-tech firms focus on creation of new technology and new products [7]. No matter the research and development of new technology or the introduction of new equipment, high-tech industries are highly dependent on capital and talent investment. On the one hand, the high risk is due to the strong uncertainty of high-tech innovation and technology development activities; on the other hand, whether the long-term marketization of new technology or new products can be successfully realized is another risk. High yields are an important feature of technological innovation in high-tech industry. Once the new technology or new product is successfully developed and recognized by the market, it can produce a high market value.

Most of the innovation comes from "reference" rather than "originality" [8]; the "silence" and "environmental sensitivity" of science and technology make technological innovation and transformation more complex than the simple process of technology introduction [9]; innovation participants need to have a certain understanding ability to absorb and apply these technologies efficiently $[10,11]$. In the process of industrialization, developing countries catch up with developed countries through technology introduction and FDI (foreign direct investment) etc., so as to improve the technological innovation ability and achieve rapid economic growth $[12,13]$. Schumpeter once pointed out that promoting innovation by technology introduction can improve innovation efficiency. High-tech industry is based on new science and technology [14], and it requires advanced science and technology to be put into the whole process of technology production, processing, outputting, and recycling of high-tech products, and technology and talents play an important role in the development of the high-tech industry.

2.2. Analytical Framework of Innovation Efficiency of the High-Tech Industry. The existing research on the efficiency evaluation of technological innovation is mainly divided into regional [15], industrial [16], and enterprise [17, 18] levels. The research on the innovation efficiency of the high-tech industry in heterogeneous regions confirms that the technological innovation efficiency varies greatly in different regions and different innovation stages, regardless of Europe or China's coastal and inland regions [19-21]. The less developed countries or regions in the late catch-up stage are not necessarily low in innovation efficiency. Through the analysis of 192 European regions' technological innovation efficiency, it is concluded that the underdeveloped regions have high efficiency [20]. From the perspective of industry, the innovation efficiency of China's high-tech industry in 2012-2018 varies greatly among different categories [21, 22]. High-tech enterprises are mainly faced with the problem of insufficient transformation ability, which leads to the low efficiency of high-tech innovation [3].

Most of the existing research studies regard the inputoutput of the high-tech industry as a whole process [23]. The characteristics of the high-tech industry determine that its technological innovation process is a complex process, and different regions, industries, and enterprises have diverse innovation characteristics. It is necessary to carry out accurate evaluation and mechanism research on the innovation efficiency of the high-tech industry.

DEA (data envelopment analysis) $[24,25]$ and SFA (stochastic frontier analysis) [26-28] have been used to measure the innovation efficiency in western developed countries and find out the factors restricting the transformation process. DEA is a scientific method of efficiency evaluation, which avoids the inaccuracy of subjective weight setting. However, in the empirical research, the input and output of DEA mainly focus on the initial input resources and final output [29]. The "black box" research method does not include the intermediate stage of transformation into the innovation chain model. With the optimization of the efficiency measurement model, based on the innovation process analysis framework, the efficiency research is divided into different stages for evaluation [30]. Focus on the substages of the innovation process and establish the relationship among different stages [31]. In this paper, the SBM method is used. According to the innovation chain of the high-tech industry, the input-output division is divided into two stages which can not only systematically grasp the total efficiency of the innovation chain but also accurately analyze the efficiency problems in different stages.

Only by scientifically evaluating the innovation efficiency of the high-tech industry can we make clear the problems existing in the innovation activities and put forward targeted suggestions to solve the problems. Existing research has provided an important basis; however, there are still controversies and problems in the existing research studies. The high-technology creation and transformation process actually a complex multistage activity, which is a multistage chain process of multiple inputs and outputs [32]. Most of the existing efficiency evaluation research studies regard the transformation process as a single input-output stage or only focus on a certain part of the overall activity. The analysis of a single stage of the transformation process ignores the systematisms and cannot evaluate efficiency pertinently.

Rothwell pointed out that technology promotion and market pull are the basis for the formation of technological innovation chain [33]. Hage and Hollingsworth proposed "idea innovation chain" and divided it into basic research 


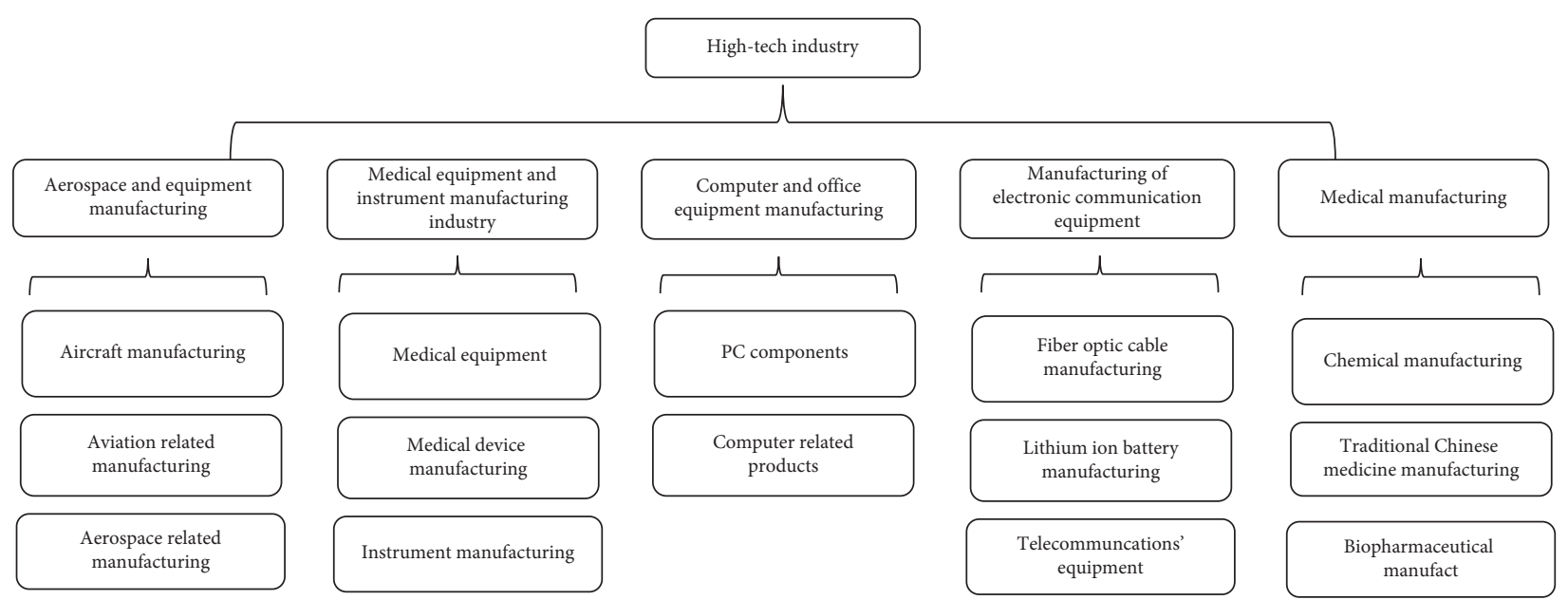

FIGURE 1: Classification of the high-tech industry in China. Source: statistical yearbook of China's high-tech industry.

[34], applied research, and development research. The existing research attempts to divide the technological innovation process of the high-tech industry into technology development and innovation transformation stages and empirically study the innovation efficiency and influencing factors of American photovoltaic industry and Chinese high-tech industry [30]. This paper focuses on the innovation efficiency of the high-tech industry and regards it as an innovation chain composed of new technology creation and transformation paths. Each stage in the whole process is an innovation aspect, and different innovation aspects are interrelated to form a complete chain of technology creation and technology marketization. This paper constructs the conceptual model of high-tech innovation process as follows (Figure 2).

From the perspective of technological innovation efficiency of the high-tech industry, what we are thinking about is not only whether higher economic or higher resources input will have better efficiency but also how the innovation efficiency improves over time and what is the difference between each innovation stage and which will then move us one step further to make clear what really matters for technological innovation efficiency improvement of the high-tech industry in China. We attempt to make a preliminary regulation summary of technological innovation efficiency improvement in different transformation stages.

\section{Methodology}

3.1. Research Method. Existing research studies analyze the innovation efficiency from perspectives of comparison of research methods, evaluation of transformation ability, and DEA efficiency evaluation $[35,36]$. The traditional DEA model normally ignores the different stages of the whole transform process and cannot measure overall efficiency of the chain process. The efficiency evaluation of multidepartment decision-making units is carried out separately, which does not consider the relationship among stages. This paper uses the SBM model [37] to deal with efficiency of subunits of interrelationship in DMU (decision-making unit), which can effectively solve the problem of intermediate investment. Tone and Tsutsui proposed the nonradial and nonangle SBM mode [38], and the advantage is that the efficiency value decreases monotonously with the change of input and output relaxation [39]. The synthetic efficiency of the SBM model can be expressed by the following equation:

$$
\begin{aligned}
& \min \rho_{0}^{*}=\frac{\sum_{k=1}^{K} w^{k}\left[1-\left(1 / m_{k}\right)\left(\sum_{i=1}^{m_{k}} s_{i o}^{k-} / x_{i o}^{k}\right)\right]}{\sum_{k=1}^{K} w^{k}\left[1+\left(1 / r_{k}\right)\left(\sum_{i=1}^{r_{k}} s_{r o}^{k+} / y_{r o}^{k}\right)\right]} \\
& \text { s.t. }\left\{\begin{array}{l}
\sum_{k=1}^{K} w^{k}=1, \quad w^{k} \geq 0(\forall k) \\
x_{0}^{k}=X^{k} \lambda^{k}+s_{0}^{k-}, \quad(k=1, \ldots, K) \\
y_{0}^{k}=Y^{k} \lambda^{k}-s_{0}^{k+}, \quad(k=1, \ldots, K) \\
e \lambda^{k}=1, \quad(k=1, \ldots, K) \\
S_{0}^{k+}, S_{0}^{k-}, \lambda^{k} \geq, \quad 0(\forall k) \\
z_{0}^{(k, h)}=Z^{(k, h)} \lambda^{h}, \quad(\forall(k, h)) \\
z_{0}^{(k, h)}=Z^{(k, h)} \lambda^{k}, \quad(\forall(k, h)),
\end{array}\right.
\end{aligned}
$$

where $\rho_{0}^{*}$ is the overall efficiency of $\mathrm{DMU}_{0}, X_{i 0}^{k} \in R_{+}^{m_{k}}$ is the input vector of $\mathrm{DMU}_{0}$ department $K, m_{k}$ is the input type of sector $K, Y_{r 0}^{k} \in R_{+}^{r_{k}}$ is the output vector of sector $K, r_{\mathrm{k}}$ is the output type of sector $k, s_{i 0}^{k-}$ and $S_{r 0}^{k+}$ are, respectively, relaxation variables of input and output, $w^{k}$ is the weight of department $k, \lambda^{k} \in R_{n}^{+}$is a nonnegative vector, $e$ is a constant, which means non-Archimedean infinitesimal, and $Z_{0}^{(k, h)}$ is the intermediate variable, which is the output of $k$ sector and the input of $h$ sector, while the model cannot distinguish difference between effective DMU. In super-SBM [37] differences between valid DMU can be distinguished. The performance of DMU in superefficiency network SBM can be expressed by equation (2). Among which $S_{i 0}^{k-*}$ and $S_{r 0}^{k+*}$ are optimal input relaxation variables and optimal output 


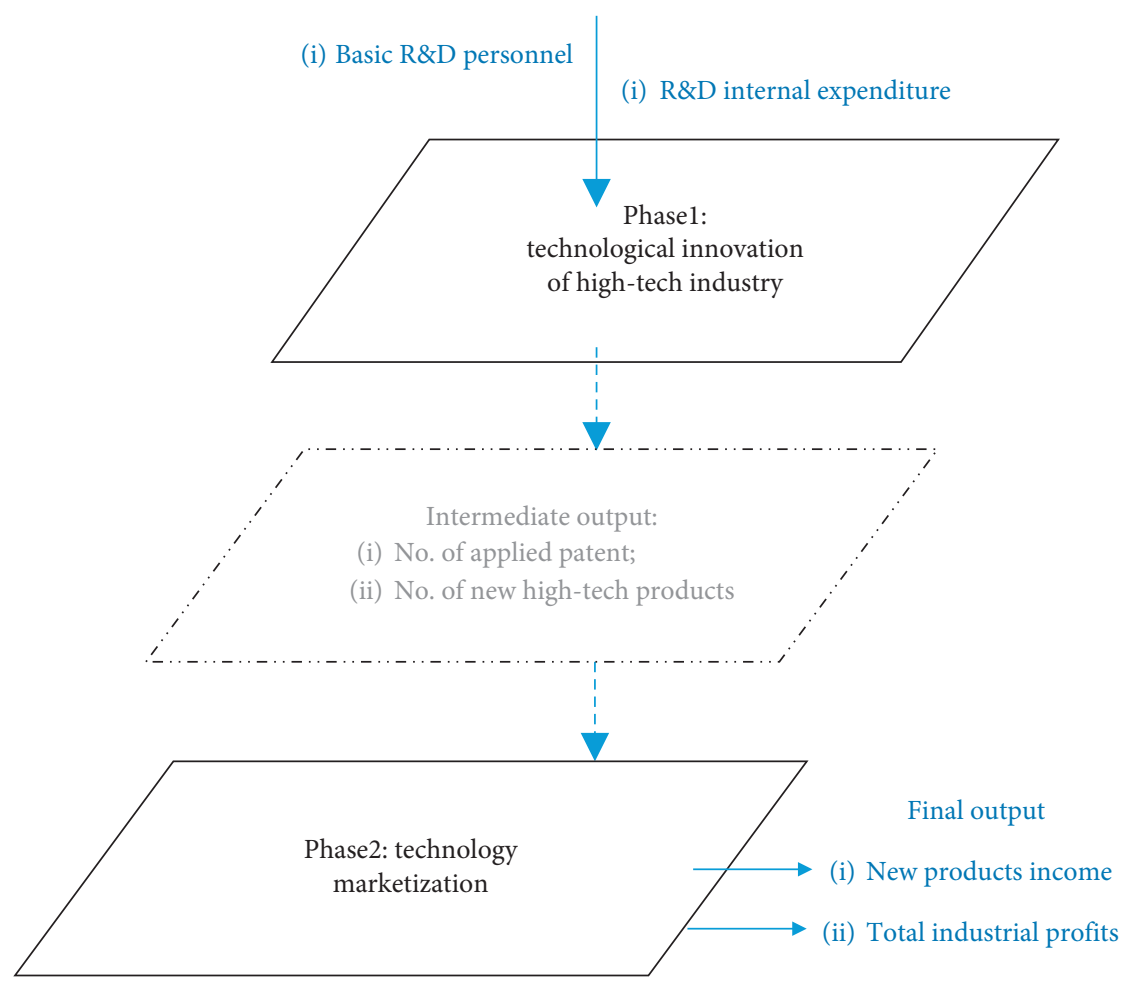

FIGURE 2: Conceptual model of technological innovation of the high-tech industry.

relaxation variables, respectively. If $\rho_{0}^{*}=1, \mathrm{DMU}_{0}$ is effective, and the performance of transformation reaches the highest level. If $\rho_{k}=1$, it shows that the $\mathrm{K}$ department in the DMU is efficient. The superefficiency network SBM model in this paper evaluates the three stages efficiency of high-tech industry transformation in Chinese. This can help to find out the problems in different high-tech transformation stages and are more accurate to find ways to improve the efficiency problem:

$$
\rho_{k}=\frac{1+\left(1 / m_{k}\right)\left(\sum_{i=1}^{m_{k}\left(s_{i o}^{k-*} / x_{i o}^{k}\right)}\right)}{1-\left(1 / r_{k}\right)\left(\sum_{r=1}^{r_{k}} s_{r o}^{k+*} / y_{r o}^{k}\right)}, \quad(k=1, \ldots, K) .
$$

From efficiency index aspect, the input-output index of existing research usually takes $R \& D$ personnel, $R \& D$ internal expenditure, applied patent [40], new products, etc. as input indicators of different efficiency calculation stages. Number of applied patents and number of new products are taken as output indicators [28, 32, 41]. In this paper, the twostage efficiency indicators are selected based on the existing research. According to the characteristics of different transformation stages and considering the relationship between stages, different input-output indicators are considered (Table 1). This paper selects 2009-2018 as the research period, and the selected indicators cover all regions in Yangtze River economic belt in China. Considering the lag feature of patent and products related data, this paper selects one-year lag patents and new products' data. Moreover, input-output data of the innovation efficiency of the hightech industry are from "Statistical yearbook of China's high technology industry (2009-2019);" data of influencing
TABLE.1: Indicator of high-tech innovation efficiency.

\begin{tabular}{lcc}
\hline Phase & Input & \multicolumn{1}{c}{ Output } \\
\hline \multirow{2}{*}{ Phase 1 } & Basic R\&D personnel & No. of applied patent \\
& R\&D internal expenditure & No. of new products \\
\hline \multirow{2}{*}{ Phase 2 } & $\begin{array}{l}\text { No. of applied patent } \\
\text { No. of new products }\end{array}$ & $\begin{array}{l}\text { New products income } \\
\text { Total industrial profits }\end{array}$ \\
\hline
\end{tabular}

factors are from "China City Statistical Yearbook (2009-2019)" and "Statistical Yearbook of China Science and Technology (2009-2019).”

(1) In high-tech innovation stage, high-tech firms or related research institute apply R\&D personnel and R\&D expenditure in process of new technology creation. After creating new inventions or technologies, enterprises will apply for patents to protect their technologies. The new technology can also be used in new high-tech products. Therefore, patents and new products are main outputs in this stage. (2) In the technology marketization stage, the aim of high-tech firms is to serve the demand of the market, and the products and technology transform into the market value. High-tech firms gain profit; therefore, new products' income and total industrial profits represent the main output in this stage.

3.2. Panel Regression. The influencing factors of regional technological innovation efficiency of the high-tech industry involve complex aspects. Based on existing research and the reality of Chinese high-tech industry, considering data availability, the innovation efficiency of two stages are selected as dependent variables, taking the government 
subsidies, R\&D intensity, enterprise scale, market structure, innovation environment, and regional openness as the influencing factors. Constructing the panel regression model of influencing factors on the efficiency of the high-tech industry innovation progress:

$$
T E_{i t}=\alpha+\beta_{1} G S_{i t}+\beta_{2} R D I_{i t}+\beta_{3} O P E N_{i t}+\beta_{4} E N V I R_{i t}+\beta_{5} M S_{i t} \text {, }
$$

where " $T E_{i t}$ " is the technology innovation efficiency of the $i$ th city in Yangtze River Economic Belt in the Tyear, " $\alpha$ " is a constant term, $\beta_{1} \ldots \beta_{5}$ is the regression coefficient of each explanatory variable, "GS $S_{i t} R D I_{i t}, O P E N_{i t}, E N V I R_{i t}$, and $M S_{i t}$ " represent government subsidies, $\mathrm{R} \& \mathrm{D}$ intensity, openness, innovation environment, market structure of the $i$ th city in the Tyear, and $\varepsilon_{i t}$ is random disturbance.

(1) Government subsidies $\left(G S_{i t}\right)$ : it is a form of financial support to the enterprise from the government, generally with the aim of promoting technological innovation. Some research studies prove positive relationship between government subsidies and innovation efficiency $[42,43]$. In the R\&D expenditure of the regional high-tech industry, the proportion of government investment is used to represent government subsidies [44].

(2) R\&D intensity $\left(R D I_{i t}\right)$ : R\&D intensity represents the technological $\mathrm{R} \& \mathrm{D}$ and innovation intensity of regional innovation participants. Innovation participants promote technological innovation through resource sharing and cooperation, which is an important indicator affecting the efficiency of technological innovation. Existing research proved that $R \& D$ intensity can reflect the impact of $R \& D$ resource on innovation effect, which is expressed by the ratio of $\mathrm{R} \& \mathrm{D}$ expenditure and regional GDP.

(3) Innovation environment $\left(E N V I R_{i t}\right)$ : regions with better innovation environment can usually gather more technical talents. Regions with better innovation environment and higher level of economic development, where people's consumption desire is stronger, can promote faster the commercialization process of new technology. Better innovation environment can also effectively promote the openness of the region. A sufficient number of R\&D institutions is very important to create a better innovation environment, which is normally expressed by the number of regional $\mathrm{R} \& \mathrm{D}$ institutions.

(4) Regional openness $\left(O P E N_{i t}\right)$ : regional openness usually helps enterprises to achieve better knowledge and technology. Especially for the high-tech industry, its knowledge intensive features need global key technology. Existing research studies normally measure regional openness by the ratio of FDI to GDP or the ratio of industrial export delivery value to main business income. Considering the innovation characteristics and data integrity of the hightech industry, this paper selects the former as the regional openness index.
(5) Market structure $\left(M S_{i t}\right)$ : market structure is usually used to measure the number and distribution of trading participants, the degree of product differentiation, industry competition, and monopoly. Existing research on China's industrial development has proved that market structure is related to industrial technical efficiency, high-tech industrial competition, and innovation [45]. Based on the existing research, this paper selects the ratio of the main business income of large and medium-sized high-tech enterprises to the total income of the main business as the analysis index

\section{Overall Innovation Efficiency of the High- Tech Industry in Yangtze River Economic Belt}

This paper uses superefficiency network SBM model to calculate the innovation efficiency of high-tech industry in Yangtze Economic Belt from 2009 to 2018. Based on the characteristics of regional heterogeneity, this paper divides Yangtze River economic belt into three regions: the Yangtze River Delta region (Yangtze River Delta region: according to "Yangtze river delta regional planning (2010)" there are one direct-controlled municipality and two provinces: Shanghai, Jiangsu, and Zhejiang, 16 core cities within this region.), the middle region (middle region contains four provinces: Anhui, Jiangxi, Hubei, and Hunan.), and the western region (western region area contains three provinces and one direct-controlled municipality: Chongqing, Sichuan, Yunnan, and Guizhou.). Due to huge regional economic heterogeneity, differences in innovation volume among regions are inevitable. Therefore, when analyzing areas with large spans and significant internal differences, we should not only focus on the absolute amount of innovation volume but also ignore question of whether knowledge or R\&D resources are reasonably configured. Therefore, when analyzing the innovation efficiency of the high-tech industry and the influence factors, this paper takes regional heterogeneity into consideration and analyzes overall efficiency and evolution characteristics of the heterogeneous region.

During 2009-2018, average high-tech efficiency of Yangtze River Delta $(0.519)$ is higher than that of middle (0.406) and western (0.477) region (Table 2). The overall efficiency of the three regions shows a slow upward trend, which indicates that the high-tech industries in the Yangtze River economic belt have gradually realized the path of efficient innovation in recent years. The technological innovation of enterprises and the marketization efficiency of new technologies and new products have also been improved. However, the whole efficiency in the Yangtze River economic belt is not high. Therefore, it is necessary to analyze the efficiency and its influencing factors in different transform stages in order to improve high-tech innovation efficiency.

From 2009 to 2018, Jiangsu has become the region with the highest high-tech innovation efficiency in Yangtze River Delta, and the average efficiency in recent ten years is 0.7 , which is much higher than the regional average level (0.519). The overall efficiency in Jiangsu has been ahead of other 
TABLE 2: Innovation efficiency of the high-tech industry in Yangtze Economic Belt from 2009 to 2018.

\begin{tabular}{lcccccccccccc}
\hline Region & 2009 & 2010 & 2011 & 2012 & 2013 & 2014 & 2015 & 2016 & 2017 & 2018 & Average \\
\hline Shanghai & 0.543 & 1.054 & 0.466 & 0.277 & 0.248 & 0.349 & 0.354 & 0.348 & 0.381 & 0.569 & 0.459 \\
Jiangsu & 0.417 & 0.739 & 0.651 & 0.550 & 1.302 & 0.643 & 0.712 & 0.659 & 0.570 & 0.762 & 0.700 \\
Zhejiang & 0.241 & 0.538 & 0.365 & 0.261 & 0.472 & 0.351 & 0.374 & 0.354 & 0.347 & 0.548 & 0.385 \\
Anhui & 0.395 & 0.364 & 0.391 & 0.414 & 0.434 & 0.518 & 0.574 & 0.462 & 0.422 & 0.773 & 0.475 \\
Delta average & 0.383 & 0.696 & 0.535 & 0.418 & 0.499 & 0.501 & 0.546 & 0.505 & 0.456 & 0.650 & 0.519 \\
Jiangxi & 0.545 & 0.495 & 0.359 & 1.000 & 0.575 & 0.631 & 0.816 & 1.028 & 0.852 & 0.680 & 0.698 \\
Hubei & 0.271 & 0.575 & 0.243 & 0.187 & 0.150 & 0.244 & 0.316 & 0.351 & 0.376 & 0.578 & 0.329 \\
Hunan & 0.343 & 1.000 & 1.345 & 1.000 & 1.000 & 0.558 & 0.500 & 0.580 & 0.334 & 0.525 & 0.719 \\
Middle average & 0.284 & 0.570 & 0.357 & 0.270 & 0.280 & 0.374 & 0.435 & 0.480 & 0.431 & 0.574 & 0.406 \\
Chongqing & 0.518 & 1.000 & 1.141 & 0.401 & 0.338 & 1.000 & 0.910 & 0.699 & 0.745 & 0.909 & 0.766 \\
Sichuan & 1.000 & 0.432 & 0.815 & 0.463 & 0.353 & 0.685 & 0.378 & 0.578 & 0.446 & 0.424 & 0.557 \\
Guizhou & 0.274 & 0.235 & 0.251 & 0.134 & 0.076 & 0.208 & 0.302 & 0.403 & 0.394 & 0.483 & 0.276 \\
Yunnan & 1.213 & 0.774 & 0.475 & 0.260 & 0.552 & 0.488 & 0.412 & 0.705 & 1.571 & 1.000 & 0.745 \\
West average & 0.378 & 0.387 & 0.656 & 0.358 & 0.284 & 0.577 & 0.494 & 0.557 & 0.505 & 0.570 & 0.477 \\
Country & 0.355 & 0.712 & 0.462 & 0.349 & 0.390 & 0.468 & 0.505 & 0.480 & 1.000 & 0.658 & 0.538 \\
\hline
\end{tabular}

Source: calculated by National Bureau of Statistics of China (NBSC), Statistical Yearbook of China's High Technology Industry, Beijing: China Statistics Press, 2009-2019.

regions in the Yangtze River Delta. The industrial development of Jiangsu has entered the postindustrialization stage, and enterprises have stronger innovation ability and better innovation environment. In 2017, there were 25,400 R\&D institutions in Jiangsu, 1.8 times more than in 2011. The number of scientific and technological personnel reached 1.22 million, an increase of $49.5 \%$ over 2011. Jiangsu's R\&D expenditure accounts for $2.7 \%$ of GDP, and the R\&D willingness of technology enterprises is higher than that of enterprises in other regions. Shanghai is China's economic and financial center with outstanding advantages in scientific research and innovation, while the efficiency of Shanghai changes from 0.543 to 0.569 . Therefore, it is urgent for Shanghai to solve the problem of insufficient high-tech innovation in order to realize the high-level development of regional innovation.

In middle regions, the overall level of GDP in Hubei is higher than that in other two regions, and the internal R\&D expenditure also has advantage, but the efficiency of hightech innovation is the lowest in the past decade. It shows that the large number of R\&D personnel and findings in Hubei have not been used efficiently. Optimizing the resource efficiency of Hubei is important to improve the overall regional high-tech innovation. The innovation efficiency of Hunan's high-tech industry is the highest (0.719), but it shows a decrease trend.

The overall high-tech efficiency of the western region is higher than that of the middle region; the innovation efficiency of the high-tech industry in Yunnan and Chongqing is higher than that in other regions. This is consistent with the conclusion that the main goal of interregional network innovation cooperation innovation of western region is to realize the new technology application and marketization [5].

Regions with relatively insufficient economic base and innovation input are not absolutely deficient in the high-tech innovation efficiency, and regions with rapid economic development and higher technology investment cannot necessarily achieved high efficiency. In the process of technological innovation of the high-tech industry, which stages really affect the improvement of regional overall efficiency? We need to think about which stages in the process really affect the efficiency improvement of the region. As the process of high-tech innovation can be divided into two main stages, technology innovation and technology marketization, this paper further attempts to analyze the stage efficiency and its main influence factors. This paper tries to find out the stage problems in high-tech innovation process in Yangtze River economic belt and puts forward some possible suggestions to improve the efficiency.

\section{Stage Analysis of Innovation Efficiency of the High-Tech Industry}

5.1. Computation of Two-Stage Innovation Efficiency. From the perspective of computation of two-stage innovation efficiency of the high-tech industry, the average efficiency level of technology innovation in Yangtze River economic belt gradually increased. The average efficiency in Yangtze River Delta, middle, and western region distinctly rise from $0.383,0.283$, and 0.377 in 2009 to $0.649,0.573$, and 0.569 in 2018 (Figure 3). From evolution perspective, Shanghai in the Yangtze River Delta has obvious advantages from 2008 to 2010. After 2012, Anhui and Jiangsu got caught up advantages; the technological innovation efficiency of the high-tech industry is constantly improving. It proves that the regional $\mathrm{R} \& \mathrm{D}$ funding and personnel have been used efficiently. However, average efficiency (0.405) of the middle region is the lowest, among which Hubei (0.329) is lower than the regional average level. The average efficiency of technological innovation in the western region $(0.476)$ is higher than that in the middle region; the average efficiency of Guizhou (0.276) is much lower than that of Chongqing (0.766), Yunnan (0.745), and Sichuan (0.557). Guizhou has become a region that needs to focus on improving the technological innovation efficiency. Therefore, how to improve the efficiency of technological innovation in the 


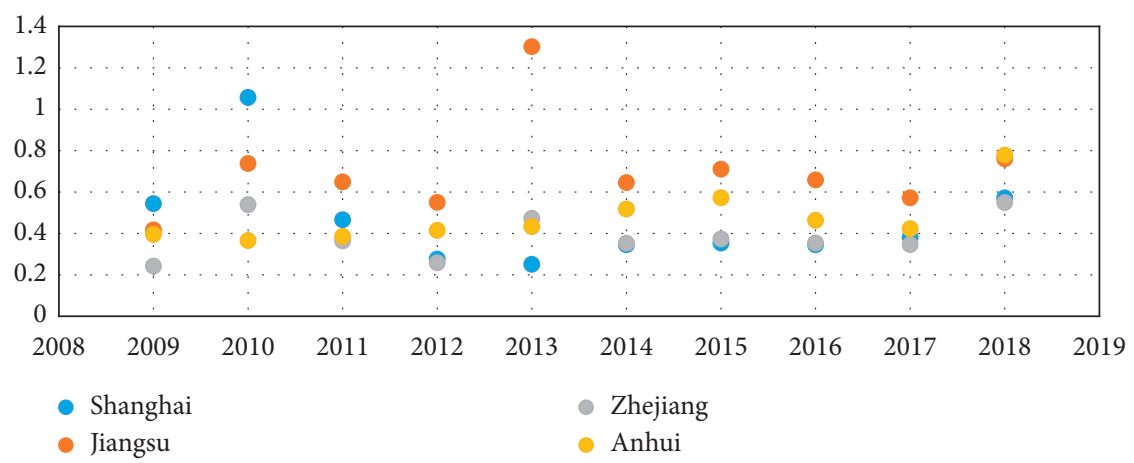

(a)

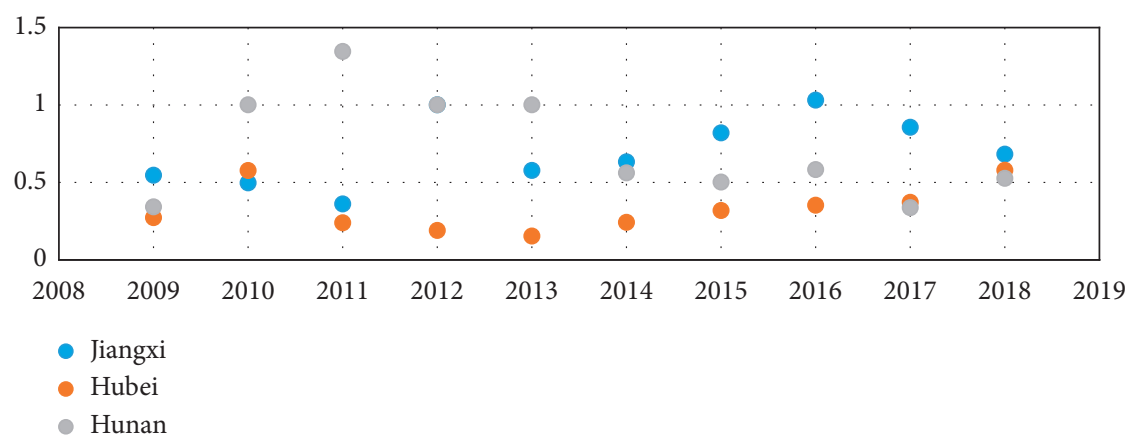

(b)

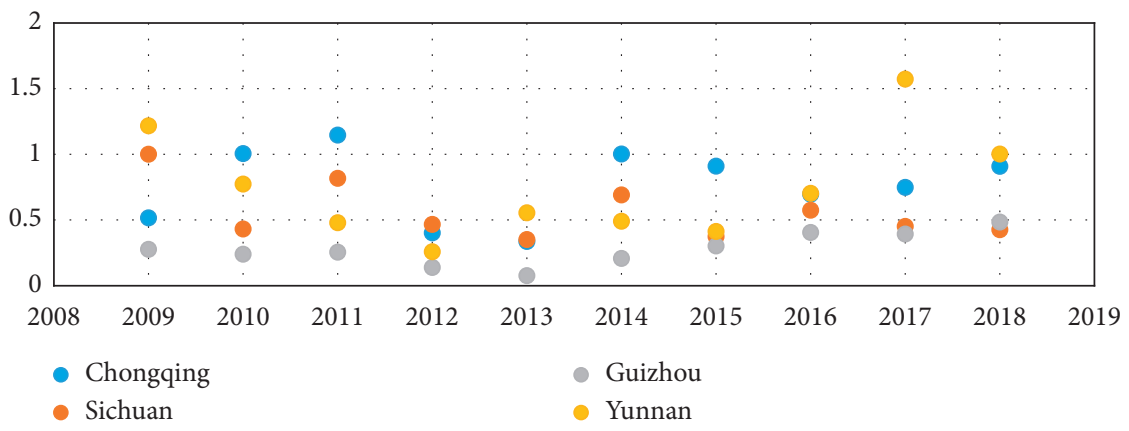

(c)

Figure 3: Efficiency of the high-tech industry in the technological innovation stage (2009-2018). (a) Stagel of Yangtze River Delta. (b) Stage1 of the Middle Region. (c) Stage1 of the Western Region. Source: calculated by National Bureau of Statistics of China (NBSC), Statistical Yearbook of China's High Technology Industry, Beijing: China Statistics Press, 2009-2019.

middle and western regions is the key to the high-tech innovation in the Yangtze River economic belt.

The marketization stage of technological achievements is the second stage of innovation efficiency evaluation of the high-tech industry. Whether the new technological or products can be successfully marketed and produce value for regions and enterprise is an important manifestation of the success technology transformation. The marketization efficiency of technological achievements in most regions of the Yangtze River economic belt shows an upward trend. From 2009 to 2018, the average efficiency of marketization stage in the Yangtze River Delta increased from 0.73 to 0.84 , the middle region increased from 0.55 to 0.78 , and the western region increased from 067 to 0.71 (Figure 4).

Within the Yangtze River Delta, Jiangsu has the highest marketization efficiency (0.99); the average marketization efficiency of Shanghai is higher than that of Anhui and Zhejiang, but the efficiency showed a decrease trend. It shows that the new technological cannot effectively match the market demand and realize technological transformation. Therefore, in order to ensure the high-quality development of regional high-tech industry, regions need to pay more attention to the reasons for the reduction of efficiency in recent years. Although Hubei and Hunan in the middle of the Yangtze River started with low market efficiency, they showed an increase trend, the efficiency values were 0.89 and 0.73 by 2018 . With the improvement of the marketization efficiency of high-tech achievements, Hunan achieved the sales revenue of 2747.835 billion yuan of high-tech products by 2018 , with an increase of $12.9 \%$. The added value of the high-tech industry in Hubei increased by $14.4 \%$. The overall efficiency trend of the western region is basically the same, 


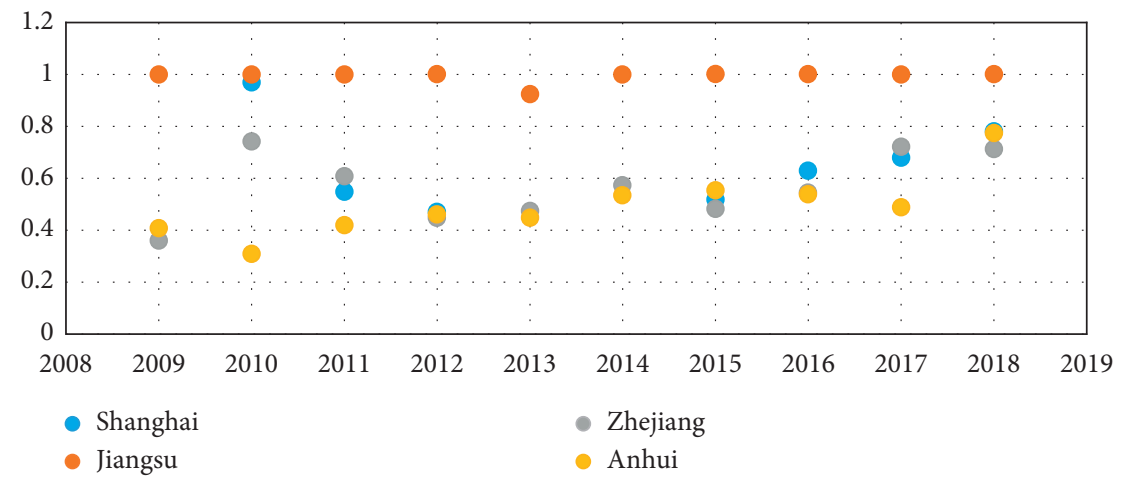

(a)

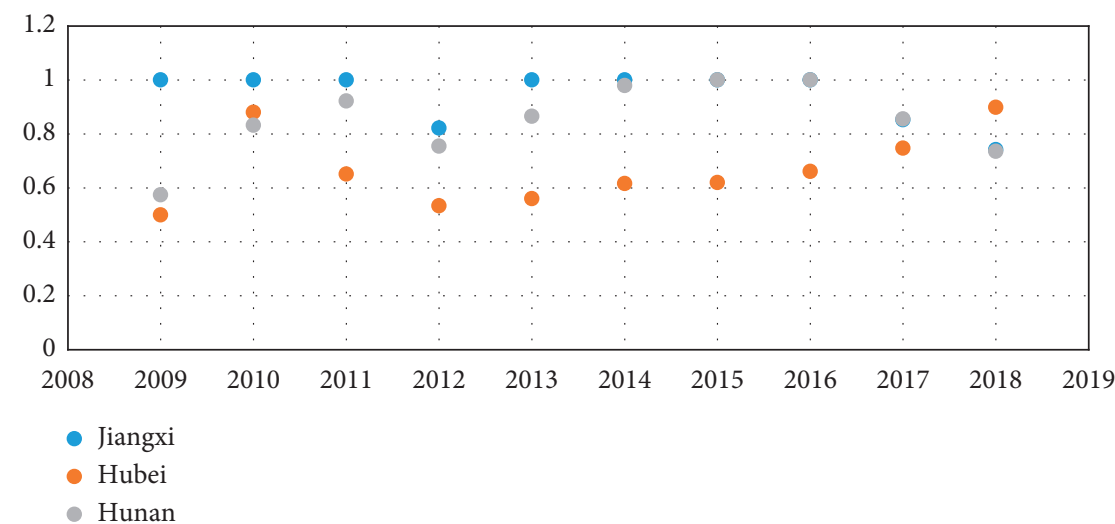

(b)

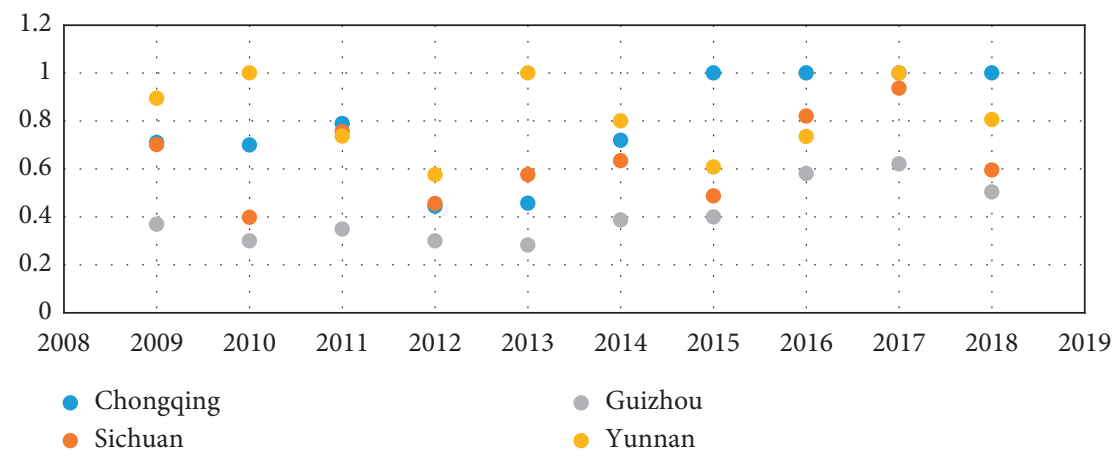

(c)

Figure 4: Efficiency of the high-tech industry in the technological marketization stage (2009-2018). (a) Stage2 of Yangtze River Delta. (b) Stage 2 of the Middle Region. (c) Stage2 of the Western Region. Source: calculated by National Bureau of Statistics of China (NBSC), Statistical Yearbook of China's High Technology Industry, Beijing: China Statistics Press, 2009-2019.

and the average level of marketization efficiency in Yunnan is higher than that in other regions (0.81). Chongqing (0.78) and Sichuan (0.63) were lower than Yunnan, and Guizhou had the lowest (0.40) marketization efficiency. Therefore, the key to improve technological innovation is to find out the reasons for the low efficiency of heterogeneous regions.

5.2. Analysis of Influencing Factors of Stage Efficiency. This part applied the panel regression model to find out the main influencing factors of high-tech innovation in the Yangtze River economic belt. The variables passed the multicollinearity and autocorrelation test, which met the requirements of panel regression. According to panel regression analysis, government subsidies show strong positive significance in both stage one and stage two, better foundation of government support is conducive to enterprise innovation investment, and higher efficiency of technological innovation is achieved (Table 3). This indicates that the national industrial support and capital investment have a positive role in promoting the technological innovation and transformation of the high-tech industry $[42,43]$. On the one hand, government subsidies provide support for technology research and development; on the other hand, it reduces the risk of technology marketization. Therefore, improving the positive guidance and support of the 
TABLE 3: Influence factor of innovation efficiency of the high-tech industry in Yangtze River economic belt.

\begin{tabular}{|c|c|c|c|c|}
\hline & \multicolumn{2}{|c|}{ Phase 1} & \multicolumn{2}{|c|}{ Phase 2} \\
\hline & Coef. & $P>|t|$ & Coef. & $P>|t|$ \\
\hline Government subsidies & $\begin{array}{c}0.110^{* * *} \\
(0.320)\end{array}$ & 0.001 & $\begin{array}{c}0.074^{* * *} \\
(0.225)\end{array}$ & 0.001 \\
\hline $\mathrm{R} \& \mathrm{D}$ intensity & $\begin{array}{c}0.118^{* * *} \\
(0.290)\end{array}$ & $\leq 0.001$ & $\begin{array}{c}0.070 \\
(0.124)\end{array}$ & 0.573 \\
\hline Innovation environment & $\begin{array}{c}0.029 \\
(0.320)\end{array}$ & 0.355 & $\begin{array}{l}0.229^{*} \\
(0.118)\end{array}$ & 0.052 \\
\hline Regional openness & $\begin{array}{c}0.024 \\
(0.193)\end{array}$ & 0.212 & $\begin{array}{c}0.044^{* * * *} \\
(0.014)\end{array}$ & 0.003 \\
\hline Market structure & $\begin{array}{c}0.064 \\
(0.869)\end{array}$ & 0.461 & $\begin{array}{c}0.060 \\
(0.059)\end{array}$ & 0.303 \\
\hline Cons & $\begin{array}{l}-1.049 \\
(0.367)\end{array}$ & 0.004 & $\begin{array}{l}-0.228 \\
(0.445)\end{array}$ & 0.608 \\
\hline $\begin{array}{l}\text { R-squared } \\
\text { Hausman P } \\
\text { Model }\end{array}$ & \multicolumn{2}{|c|}{$\begin{array}{c}0.282 \\
0.0607\end{array}$} & & \\
\hline
\end{tabular}

${ }^{*}$ denotes $P<0.1,{ }^{* *}$ denotes $P<0.05$, and ${ }^{* * *}$ denotes $P<0.01$. Number of observations: 110 . Source: calculated by (1) National Bureau of Statistics of China (NBSC), Statistical Yearbook of China's High Technology Industry, Beijing: China Statistics Press, 2009-2019, (2) National Bureau of Statistics of China (NBSC), China City Statistical Yearbook, Beijing: China Statistics Press, 2009-2019, and (3) National Bureau of Statistics of China (NBSC), Statistical Yearbook of China Science and Technology, Beijing: China Statistics Press, 2009-2019.

government plays a positive role in improving the innovation efficiency of the regional high-tech industry.

The effect of $R \& D$ intensity on regional high-tech industry innovation is in the stage of industrial technology innovation, and the effect is significant. The investment characteristics of the high-tech industry require large amount of capital investment in its technological innovation activities. The higher the investment intensity of high-tech $\mathrm{R} \& \mathrm{D}$, the more likely it is to improve its innovation level, so as to improve the efficiency of technological innovation. The significance of $\mathrm{R} \& \mathrm{D}$ intensity shows that the increase of $\mathrm{R} \& \mathrm{D}$ investment in the Yangtze River economic belt is not only conducive to regional technology innovation but also has a positive impact on the management of high-tech enterprises and the overall innovation system, promoting the efficiency of technological innovation. This plays an important role in improving innovation efficiency.

Regional openness has a strong positive impact on the transformation and marketization stage of innovation. The high-tech industry is a technology intensive industry, and technology transformation activities cannot be completed by a single organization or a single region. High-tech transformation and marketization are interregional and global technological activities, which can be realized through interregional cooperation of technological innovation organizations. With the improvement of regional openness, high-tech firms can have more opportunities to participate in international industry cooperation and realize international technology innovation. The improvement of international relations also requires firms to continuously improve the technology transformation efficiency, so as to better meet the requirements of participating in international knowledge competition and global markets.

Innovation environment has a positive impact on the transformation and marketization stage of innovation. The increase and agglomeration of R\&D institutions significantly improve the allocation and transformation efficiency of innovation resources. This also shows that the increase in the number of regional $\mathrm{R} \& \mathrm{D}$ institutions can provide a better innovation environment for high-tech enterprises [46]. At the same time, it can provide technology resources and innovation platform and form better technology transformation system. Regional high-tech enterprises implement technological innovation through cooperative innovation or technology trading, so as to improve the efficiency of technology marketization.

There is positive relationship between market structure and technological innovation of regional high-tech industry, but the impact is still not significant. It indicates that the market structure can reflect the competition of high-tech enterprises to a certain extent. Optimizing the market structure can promote the efficiency of high-tech innovation, and the results also show the competitive advantage of foreign-funded enterprises in the high-tech market. Although the proportion of large and medium-sized stateowned high-tech enterprises in China is high, they still need to further improve their technology market competition and influence. Only in this way can Chinese high-tech enterprises play a stronger role in adjusting the structure of technology market and improving the efficiency of technological innovation.

\section{Conclusion and Discussion}

This paper proposed the two-stage efficiency analytical framework for regional technology innovation of the hightech industry in Yangtze River Economic Belt, which regards the innovation activity as a complex process with mutual relations. The whole process is divided into two main stages: technology innovation and technology marketization. The super-SBM model is used to estimate efficiency of technology innovation activities of the high-tech industry in 
Yangtze River economic belt. It is helpful to accurately measure both the stage efficiency and the whole process in heterogeneous region in China.

(1) The whole efficiency of high-tech innovation in the Yangtze River economic belt has been improved, but there are great differences within regions. Therefore, the heterogeneous regional innovation context should be taken into consideration in the institutional management of regional and industrial policies. The high-tech innovation efficiency in Yangtze River economic belt is not high, but in recent years, the efficiency has been gradually improved. It must be admitted that the R\&D resources invested in regional high-tech enterprises in Yangtze River economic belt are getting more efficiently utilized. There are regional efficiency differences within the Yangtze River economic belt, the efficiency of Yangtze River Delta is slightly higher than that of the central and western regions, and the innovation efficiency of in the central region is the lowest. Shanghai is the financial center of China, with outstanding economic and technology research advantages. How to realize high innovation efficiently and avoid waste or redundancy of resources is the main problem.

There is a certain correlation between the economic foundation and overall innovation efficiency, which has been proved by existing research. However, the efficiency with insufficient economic foundation is not necessarily low. The innovation and transformation of high technology should not only focus on whether there is large amount of funds or personnel input. In order to effectively promote technology innovation and avoid waste of R\&D resources, targeted adjustment should be made according to the regional heterogeneity and transformation stage.

(2) From perspective of the high-tech innovation stage, there is a significant positive correlation between government subsidies and R\&D intensity to improve the efficiency of regional high-tech innovation, and the government subsidy continues to play a positive role in the technology marketization stage. Generally, government support is still crucial to the innovation and marketization of China's high-tech industry. Therefore, in order to realize the reginal and enterprise innovation and transformation, the government needs to carry out appropriate policy guidance, increase financial support for high-tech enterprises, and encourage high-tech enterprises to realize technological innovation by increasing R\&D investment.

Combined with the regional heterogeneity of the high-tech innovation stage in the Yangtze River economic belt, the technological innovation efficiency of the Yangtze River Delta is higher than that of the middle and western regions. This is mainly because the government support and R\&D investment in the Yangtze River Delta are much higher than those in the central and western regions. Although the economic foundation and R\&D resources of the middle and western regions do not have comparative advantages, however, the government can actively guide by building the policy management system and encourage enterprises to increase the proportion of $\mathrm{R} \& \mathrm{D}$ investment, so as to improve the efficiency of technological innovation by enhancing the R\&D intensity of enterprises.

(3) From perspective of the high-tech marketization stage, technology transformation and successful marketization is the key to reflect the value of new technology and products in high-tech enterprise. In the new technology marketization stage, in addition to government support and the regional and enterprises openness, better innovation environment also plays positive role. Innovative high technology usually not only serves the local market but also realizes its value through interregional cooperation and transaction. Therefore, openness is very important for the establishment of interregional cooperation or transnational relationships. On the one hand, the existing interregional relationship has realized the marketization of new technology, On the other hand, it also helps to build more market relations, which forms a virtuous circle of technology marketization. The innovation environment can help form innovative talents pool and help enterprises to form cooperative relationship with technology R\&D or transformation institutions. This relationship will also help to bridge interregional connection, which will strengthen the external linkages and further contribute to the long-distance technology marketization process.

Combined with the characteristics of technology marketization in the heterogeneous regions of the Yangtze River economic belt, the efficiency of marketization of technology achievements of hightech enterprise in the Yangtze River economic belt has risen slowly, which shows that high-tech firms in China gradually have the ability of combining technology creation with practice and creating market value. The average efficiency of marketization in Yangtze River Delta is the highest, which is related to the well-developed headquarters economy, agglomeration of high-tech enterprises, $R \& D$ institutions, $R \& D$ talents, and significant advantages of FDI. In terms of policy-making, and it is necessary to learn from technology marketization advantage regions. The government needs to guide high-tech enterprises to pay more attention to the integration of interregional resources. Marketization efficiency can be improved by constructing the interregional transformation platform and cooperation system. At the same time, enterprises are encouraged to create 
better innovation ecological, overcome their own disadvantages and improve innovation efficiency through the increase of $\mathrm{R} \& \mathrm{D}$ intensity.

(4) China's high-tech innovation and marketization efficiency still need to be optimized. On the one hand, national and local governments need to provide support for high-tech innovation by policy guidance and financial support. On the other hand, the technology marketization efficiency can be improved by the construction of interregional technology cooperation and technology transformation system. The R\&D resource of China's high-tech enterprises has not yet reached the optimal level and needs further optimized. High tech enterprises should not only pay attention to the quantity of innovation output but also pay attention to the optimal of interregional resources. Regions with relatively insufficient development advantages can promote innovation efficiency by enhancing R\&D intensity.

Sometimes, high-tech enterprise has rich innovation output, but these outputs have not been successfully transformed into market value due to their quality or tech level. This requires enterprise to pay more attentions on interregional or international cooperation to access key technology to meet the market demand and to avoid the dilemma that the quantity of technology achievements is large, but it is difficult to transform to market value. Moreover, it is necessary to enhance the technology innovation ability of high-tech enterprise, produce highlevel technology achievements, and strengthen the transformation and marketization of new technology and products. Creating real market value for regional economy is the key to Chinese high-tech enterprise in the future.

Innovation and technology creation are the key to triggering fundamental economic and social changes [47]. Enterprises are key members of innovation system in high-tech industry, and regions are considered as important space carriers for technology innovation activities. Regional innovation system is composed of enterprises, universities, and research institutions, which can continuously produce innovation [48]. Technology and new products creation and marketization of enterprises and other organizations in regional innovation system are conducive to the improvement of innovation efficiency in the region. Therefore, the analysis and mechanism exploration of high-tech enterprise technology creation and marketization will help to understand and improve regional innovation.

Realization of technology innovation activity is a complex process. Due to data availability, there are still some limitations in selection of indicators in influence mechanism analysis. Moreover, analysis of spatial heterogeneity only compares differences in two transformation stages, but does not take internal spatial interaction and the network relationship into consideration. These will be the discussion points of our further research.

\section{Data Availability}

The data used to support the findings of the study can be obtained from the corresponding author upon request.

\section{Conflicts of Interest}

The authors declare that they have no conflicts of interest.

\section{Acknowledgments}

This work was supported by National Natural Science Foundation of China (41771143 and 41801109), China Scholarship Council Postdoctoral Foundation (Grant 202008310025), and Fundamental Research Funds for the Central Universities (Grant 2020ECNU-HWFW005).

\section{References}

[1] L. Cui, R. Li, M. Song, and L. Zhu, "Can China achieve its 2030 energy development targets by fulfilling carbon intensity reduction commitments?" Energy Economics, vol. 83, pp. 6173, 2019.

[2] M. Ahmad, P. Jiang, M. Murshed et al., "Modelling the dynamic linkages between eco-innovation, urbanization, economic growth and ecological footprints for G7 countries: does financial globalization matter?" Sustainable Cities and Society, vol. 70, Article ID 102881, 2021.

[3] Q. Wang, Y. Hang, L. Sun, and Z. Zhao, "Two-stage innovation efficiency of new energy enterprises in China: a nonradial DEA approach," Technological Forecasting and Social Change, vol. 112, pp. 254-261, 2016.

[4] D. Feng, Q. Chen, M. Song, and L. Cui, "Relationship between the degree of internationalization and performance in manufacturing enterprises of the Yangtze river delta region," Emerging Markets Finance and Trade, vol. 55, no. 7, pp. 1455-1471, 2019.

[5] L. Zou and Yi-w. Zhu, "Research on innovation performance in heterogeneous region: evidence from yangtze economic belt in China," Complexity, vol. 2020, Article ID 8659134, 9 pages, 2020.

[6] L. Liu, Y. Hou, X. Zhan et al., "Innovation efficiency of hightech SMEs listed in China: its measurement and antecedents," Discrete Dynamics in Nature and Society, vol. 2020, Article ID 8821950, 9 pages, 2020.

[7] D. E. Heckler, "High-technology employment: a NAICSbased update," Monthly Labor Review, vol. 128, p. 57, 2005.

[8] J. G. March and H. A. Simon, Organizations, John Wiley \& Sons, Hoboken, NJ, USA, 1958.

[9] R. E. Evenson and L. E. Westphal, "Chapter 37 Technological change and technology strategy," Handbook of Development Economics, vol. 3, pp. 2209-2299, 1995.

[10] W. M. Cohen and D. A. Levinthal, "Absorptive capacity: a new perspective on learning and innovation," Administrative Science Quarterly, vol. 35, no. 1, pp. 128-152, 1990.

[11] M. Albert and S. Laberge, "The legitimation and dissemination processes of the innovation system Approach," Science, Technology, \& Human Values, vol. 32, no. 2, pp. 221-249, 2007.

[12] R. R. Nelson and E. S. Phelps, "Investment in humans, technological diffusion, and economic growth," The American Economic Review, vol. 56, no. 1/2, pp. 69-75, 1966. 
[13] P. Moser, "Patents and innovation: evidence from economic history," Journal of Economic Perspectives, vol. 27, no. 1, pp. 23-44, 2013.

[14] J. Schumpeter, Capitalism, Socialism and Democracy, Harper, NY, USA, 1942.

[15] J. Guan and K. Chen, "Measuring the innovation production process: a cross-region empirical study of China's high-tech innovations," Technovation, vol. 30, no. 5-6, pp. 348-358, 2010.

[16] J. Schmidt-Ehmcke and P. Zloczysti, "Industries at the world technology frontier: measuring R\&D efficiency in a nonparametric DEA framework," 2011, https://ideas.repec.org/p/ cpr/ceprdp/8579.html.

[17] E. Revilla, J. Sarkis, and A. Modrego, "Evaluating performance of public-private research collaborations: a DEA analysis," Journal of the Operational Research Society, vol. 54, no. 2, pp. 165-174, 2003.

[18] N. O’Regan, A. Ghobadian, and D. Gallear, "In search of the drivers of high growth in manufacturing SMEs," Technovation, vol. 26, no. 1, pp. 30-41, 2006.

[19] T. Broekel, N. Rogge, and T. Brenner, "The innovation efficiency of German regions - a shared-input DEA approach," Review of Regional Research, vol. 38, no. 1, pp. 77-109, 2018.

[20] K. Kalapouti, K. Petridis, C. Malesios et al., "Measuring efficiency of innovation using combined Data Envelopment Analysis and Structural Equation Modeling: empirical study in EU regions," Annals of Operations Research, vol. 294, pp. 1-24, 2017.

[21] E. G. Carayannis, E. Grigoroudis, and Y. Goletsis, "A multilevel and multistage efficiency evaluation of innovation systems: a multiobjective DEA approach," Expert Systems with Applications, vol. 62, pp. 63-80, 2016.

[22] Y. Wang, J.-f. Pan, R.-m. Pei, B.-W. Yi, and G.-l. Yang, "Assessing the technological innovation efficiency of China's high-tech industries with a two-stage network DEA approach," Socio-Economic Planning Sciences, vol. 71, Article ID 100810, 2020.

[23] E. González and F. Gascón, "Sources of productivity growth in the Spanish pharmaceutical industry (1994-2000)," Research Policy, vol. 33, no. 5, pp. 735-745, 2004.

[24] J. C. C. B. Soares de Mello, L. Angulo Meza, J. Q. da Silveira, and E. G. Gomes, "About negative efficiencies in Cross Evaluation BCC input oriented models," European Journal of Operational Research, vol. 229, no. 3, pp. 732-737, 2013.

[25] W. Chapple, A. Lockett, D. Siegel, and M. Wright, "Assessing the relative performance of U.K. university technology transfer offices: parametric and non-parametric evidence," Research Policy, vol. 34, no. 3, pp. 369-384, 2005.

[26] D. Aigner, C. A. K. Lovell, and P. Schmidt, "Formulation and estimation of stochastic frontier production function models," Journal of Econometrics, vol. 6, no. 1, pp. 21-37, 1977.

[27] D. Siegel, M. Wright, W. Chapple et al., "Assessing the relative performance of university technology transfer in the US and UK: a stochastic distance function approach," Economics of Innovation and New Technology, vol. 17, no. 7-8, pp. 717-729, 2008.

[28] D. S. Siegel, D. Waldman, and A. Link, "Assessing the impact of organizational practices on the relative productivity of university technology transfer offices: an exploratory study," Research Policy, vol. 32, no. 1, pp. 27-48, 2003.

[29] C. Kao, "Efficiency decomposition in network data envelopment analysis: a relational model," European Journal of Operational Research, vol. 192, no. 3, pp. 949-962, 2009.
[30] S. Jayanthi, E. C. Witt, and V. Singh, "Evaluation of potential of innovations: a DEA-based application to U.S. Photovoltaic industry," IEEE Transactions on Engineering Management, vol. 56, no. 3, pp. 478-493, 2009.

[31] C. Kao and S.-N. Hwang, "Efficiency decomposition in twostage data envelopment analysis: an application to non-life insurance companies in Taiwan," European Journal of Operational Research, vol. 185, no. 1, pp. 418-429, 2008.

[32] J. G. Thursby and M. C. Thursby, "Who is selling the ivory tower? Sources of growth in university licensing," Management Science, vol. 48, no. 1, pp. 90-104, 2002.

[33] R. Rothwell, "Successful industrial innovation: critical factors for the 1990s," R\&D Management, vol. 22, no. 3, pp. 221-240, 1992.

[34] J. Hage and J. R. Hollingsworth, "A strategy for the analysis of idea innovation networks and institutions," Organization Studies, vol. 21, no. 5, pp. 971-1004, 2000.

[35] K. L. Poh, B. W. Ang, and F. Bai, "A comparative analysis of R\&D project evaluation methods," R\&D Management, vol. 31, no. 1, pp. 63-75, 2001.

[36] S. Y. Sohn and T. H. Moon, "Decision Tree based on data envelopment analysis for effective technology commercialization," Expert Systems with Applications, vol. 26, no. 2, pp. 279-284, 2004.

[37] K. Tone, "A slacks-based measure of efficiency in data envelopment analysis," European Journal of Operational Research, vol. 130, no. 3, pp. 498-509, 2001.

[38] K. Tone and M. Tsutsui, "Dynamic DEA with network structure: a slacks-based measure approach," Omega, vol. 42, no. 1, pp. 124-131, 2014.

[39] G. Mei, L. Dong, T. Chengshi et al., "The research for Liaoning environmental efficiency and spatial-temporal differentiation," Geographical Research, vol. 33, no. 12, pp. 2345-2357, 2014.

[40] M. Crosby, "Patents, innovation and growth," Economic Record, vol. 76, no. 234, pp. 255-262, 2000.

[41] Yu. Fan, "Research on regional differences and influencing factors of technology transfer efficiency in Universities," Scientific Research, vol. 33, no. 12, pp. 1805-1812, 2015, in Chinese.

[42] W. Raymond, P. Mohnen, and F. C. Palm, Innovative Sales, R\&D and Total Innovation Expenditures: Panel Evidence on Their Dynamics, United Nations University, Maastricht Economic and Social Research and Training Centre on Innovation and Technology, Tokyo, Japan, 2009.

[43] M. Hud and K. Hussinger, "The impact of R\&D subsidies during the crisis," Research Policy, vol. 44, no. 10, pp. 1844-1855, 2015.

[44] C. Bérubé and P. Mohnen, "Are firms that receive R\&D subsidies more innovative?" Canadian Journal of Economics/ Revue Canadienne D'économique, vol. 42, no. 1, pp. 206-225, 2009.

[45] P. Aghion, J. Cai, M. Dewatripont, L. Du, A. Harrison, and P. Legros, "Industrial policy and competition," American Economic Journal: Macroeconomics, vol. 7, no. 4, pp. 1-32, 2015.

[46] E. Brandt, J. Messeter, and T. Binder, "Formatting design dialogues - games and participation," Co-Design, vol. 4, no. 1, pp. 51-64, 2008.

[47] J. Schumpeter, The Theory of Economic Development, Harvard University Press, Cambridge, MA, USA, 1934.

[48] P. Cooke, "Regional innovation systems: development opportunities from the 'green turn'," Technology Analysis \& Strategic Management, vol. 22, no. 7, pp. 831-844, 2010. 